\title{
Primary Lymphoepithelioma-like Carcinoma of the Lung in Singapore-A Rare Malignancy
}

Jason D'Souza

Tan Tock Seng Hospital

Dessmon YH Tai

Tan Tock Seng Hospital

Jens Samol

Johns Hopkins Singapore International Medical Centre

Soon Keng Goh

Tan Tock Seng Hospital

Ai Ching Kor

Tan Tock Seng Hospital

Ying Kiat Zee

Mount Elizabeth Hospital: Mount Elizabeth Medical Centre

Daniel Chan

Mount Elizabeth Hospital: Mount Elizabeth Medical Centre

Jan Wen Su

Mount Elizabeth Hospital: Mount Elizabeth Medical Centre

Kian Chung Ong

Mount Elizabeth Hospital: Mount Elizabeth Medical Centre

Akash Verma ( $\sim$ akashverma100@hotmail.com )

Mount Elizabeth Hospital: Mount Elizabeth Medical Centre https://orcid.org/0000-0002-7000-8708

\section{Research}

Keywords: LELC, EBUS- TBNA, cancer, chemotherapy, EBV

Posted Date: February 23rd, 2021

DOl: https://doi.org/10.21203/rs.3.rs-240838/v1

License: (1) This work is licensed under a Creative Commons Attribution 4.0 International License.

Read Full License 


\section{Abstract}

Background: Primary lymphoepithelioma-like carcinoma (LELC) of the lung is a rare histological type of lung cancer with a relatively better prognosis. It is common in Chinese population, is associated with Epstein Barr Virus (EBV), and has morphological similarities to nasopharyngeal carcinoma.

Methods: We retrospectively analysed medical records of patients with LELC at Tan Tock Seng Hospital, Singapore from November 2010 to January 2016 and evaluated baseline characteristics, staging, therapeutic interventions and survival.

Results: Ten patients were diagnosed with pulmonary LELC, all were Chinese. The median age (range) at diagnosis was 62 (42-88) years, with a female preponderance ratio of 4:1. All had Epstein-Barr virus encoded small non-polyadenylated ribonucleic acid positive status. Six (60\%) patients had stage IV, 3 (30\%) stage IIIA, and 1 (10\%) stage IIA disease. The median overall survival was 24.2 (4.7-59.4) months; in stage II, IIIA, and IV it was 27.6, 20.7 (19.8-48.9), and 26.6 (4.7-59.4) months respectively. The 1-year, 2year, 3-year, and 5 -year survival rate was $90 \%, 50 \%, 30 \%$, and $10 \%$ in the whole group, but $100 \%, 43 \%$, $28.6 \%$, and $14.3 \%$ in 7 patients who received chemotherapy. Gemcitabine/carboplatin was the most commonly used $1^{\text {st }}$ line chemotherapy.

Conclusion: LELC is associated with Chinese ethnicity, younger age of onset, EBV, lack of smoking, advanced stage, and better prognosis than other subtypes of lung cancers. For improving outcomes, future efforts should focus on increased awareness, early diagnosis, development of an ASEAN registry and international collaboration. Options such as EBV-directed adopted immunotherapy or the role of EBV vaccine also merit evaluation.

\section{Introduction}

Lung cancer remains the cancer with highest mortality rate both globally and in Singapore causing more deaths than breast, prostate, colon, and pancreas cancer combined [1]. Histologically, adenocarcinoma is the most common subtype ( $41 \%)$ followed by small cell carcinoma $(20 \%)$, squamous cell carcinoma $(12 \%)$, large cell carcinoma and others (8.4\%), and unspecified (16.3\%) histology [2].

Primary pulmonary lymphoepithelioma-like lung cancer (LELC) is a rare subtype of non-small cell lung cancer (NSCLC), representing only $0.4 \%$ of all NSCLC. It is a subtype of large cell carcinoma of the lung, according to the World Health Organization histological classification [3]. However, in terms of prognosis and in contrast to other subtypes of lung cancer, LELC exhibits an improved prognosis with multimodality treatment $[4,5]$. The median overall survival for untreated advanced NSCLC is 6 months, and if treated with chemotherapy or tyrosine kinase inhibitors (TKl`s) is 1 year or 15.4 months respectively [6, 7]. The overall 1-year, 2-year, and 3-year survival rate in patients with advanced stage NSCLC treated with chemotherapy is $28.9 \%, 7.9 \%$, and $3.3 \%$ [6,7]. Contrary to this, median survival for advanced LELC described in the largest study of 52 patients to date is much higher at 39.1 months with 1-year, 2-year, and 3 -year survival of $100 \%, 76 \%$, and $61 \%$ respectively [8]; although, not quite as good as for 
nasopharyngeal carcinomas (NPC) which has a 5 year overall survival in stage I and II of $90 \%$ and in metastatic stage III and IV of $60 \%[8,33]$.

With regards to general characteristic and demographic features, while the median age of lung cancer is 70 years, LELC presents early and it is not associated with smoking. Instead, it has morphological similarities to undifferentiated carcinoma or nasopharyngeal carcinoma (NPC) shown to be associated with Epstein Barr Virus (EBV). LELC belong to the EBV-driven cancers such as NPC, Burkitt's lymphoma, post-transplant lymphoproliferative diseases (PTLDs), Hodgkin's lymphoma, and a few gastric carcinomas $[9,10]$. Both its association with EBV and its incidence is more common in Asian compared to western population [11].

Despite EBV being prevalent worldwide, the geographic variation in the incidence of EBV related malignancies such as LELC in Chinese, nasopharyngeal carcinoma (NPC) in Southern Chinese people, Burkitt's lymphoma (BL) in sub-Saharan Africa, and infectious mononucleosis in teenagers and young adults in western countries, raises the possibility of genetic variation of EBV in different parts of the world [12]. In addition, Tzellos \& Farrell described that a specific mutation of the EBV- EBNA3B gene (a tumour suppressor gene) may be linked to development of diffuse large $B$ cell lymphoma (DLBCL) in a mouse model [12], demonstrating the potential different role viral genomic mutations may play in human disease around the globe.

LELC's better prognosis, younger age of onset, an association with EBV, and lack of an association with smoking, clearly sets LELC apart from other subset of lung cancers. However, the development of optimal treatment strategies and regimen have been fraught by its extremely low incidence $(<200$ cases have been described to date worldwide) and predominance in emerging economies such as China, Taiwan, and Hong Kong $[5,13,14]$. Therefore, the limited literature on optimal therapeutic management, prompted us to evaluate the disease characteristics, behaviour, staging, therapeutic interventions and outcomes of LELC in our local population.

\section{Methods}

We retrospectively analysed medical records of patients with biopsy proven LELC, at our centre from November 2010 to January 2016. Diagnosis of LELC was based on the established WHO criteria. All patients were screened for and found to be negative for co-existing NPC. Data was collected on age, gender, history of smoking, ECOG status, serum albumin levels at diagnosis, tumour size and location, mode of diagnostic investigation, staging, EBV encoded small non-polyadenylated ribonucleic acid in situ hybridization (EBER-ISH) status and sites of metastasis among stage IV disease. Staging was based on seventh edition of the American Joint Committee cancer staging system. Therapeutic modalities and outcomes were described with respect to progression free survival and median survival from time of diagnosis up to December 2016. Approval from the institutional ethics review board was obtained. 
We used software (SPSS, version 17; SPSS, Chicago, III) for all statistical analyses. The results were compared using a Wilcoxon two-sample test. $P$ values were two sided and considered indicative of a significant difference if less than .05. Kaplan-Meier survival analysis was performed to obtain progression free survival and overall survival.

\section{Results}

Ten patients were diagnosed with primary pulmonary LELC during the study period and all were Chinese. The median age (range) at diagnosis was 62 (42-88) years with a female preponderance ratio of 4:1. Seven patients were non-smokers. ECOG score was 0 in six and 1 in four patients. Eight of the patients had an abnormal chest radiograph at first presentation, and 1 patient had a cystic mediastinal mass detected incidentally on endoscopic ultrasound (EUS). Tumour size was $>3 \mathrm{~cm}$ in 9 patients. Five patients were diagnosed by endobronchial ultrasound trans-bronchial needle aspiration (EBUS-TBNA) and three by transthoracic needle aspiration of lung mass. The remaining 2 were confirmed from biopsy of a metastatic site and resected specimen. Six patients were staged as metastatic cancer, while three were stage IIIA and one was stage IIA. The commonest metastatic sites among those with stage IV disease were lymph nodes and bone. Serum albumin was noted to be low $(<3.7 \mathrm{~g} / \mathrm{dl})$ in 7 patients (Table 1).

Seven patients with primary pulmonary LELC received chemotherapy and five of them had gemcitabine/carboplatin as first line (Table 2). One received gemcitabine/cisplatin, and another received cisplatin/pemetrexed/bevacizumab as the first line agents. All treated patients had progression of disease requiring second line chemotherapy and three patients required further lines of chemotherapy. The average duration of freedom from progression after first line chemotherapy was 8.4 months. Five patients received palliative radiotherapy to sites of metastases and one underwent palliative hypophysectomy for metastasis to the pituitary gland.

Three patients in total, and 2 out of 7 who received chemotherapy were alive by October 2019. One patient was diagnosed to have mediastinal LELC, and underwent surgical resection. Subsequent thoracic imaging in 13 months revealed disease free status, suggesting that curative surgery in early disease should be considered. Our cohort had a median (range) overall survival of 24.2 (4.7-59.4) months. Among all patients, the 1-year, 2-year, 3-year, and 5-year survival rates were 90\%, 50\%, 30\%, and 10\%, whilst for the 7 patients with advanced LELC treated with chemotherapy (with or without radiotherapy), the 1-year, 2year, 3-year and 5-year survival rates were $100 \%, 43 \%, 28.6 \%$, and $14.3 \%$ respectively.

Of the 7 patients who had died, one was deemed unsuitable for chemotherapy, while two had declined chemotherapy. Two patients treated with palliative chemotherapy progressed and died after third line therapy (Fig. 1).

\section{Case Descriptions}


Case summary of a representative case along with radiographic and histological images are described below to illustrate the clinical profile of this cancer. A 63-year old Chinese male, ex-smoker with ECOG-1 status, was noted to have a right lung mass on chest radiograph on admission in November 2014. Computed tomography (CT) thorax revealed a $9.7 \times 7.5 \times 8.5 \mathrm{~cm}$ right lung lower lobe mass and metastatic deposits in liver and bone. He underwent endobronchial ultrasound guided transbronchial needle aspiration (EBUS-TBNA) for diagnostic confirmation of stage IV pulmonary LELC. He was started on palliative gemcitabine + carboplatin in Dec 2014 followed by a chemo-break and was re-challenged with gemcitabine + carboplatin in August 2015, achieving a remission until Dec 2016 (Fig. 2). The EBERISH was positive on histopathology (Fig. 3).

\section{Discussion}

The overall incidence of primary pulmonary LELC is low. The highest incidence is found in the Chinese population. In Singapore, $76 \%$ of the population is Chinese, but, as little is known about the incidence of LELC in Singapore, we sought to study the characteristics, behaviour, and outcomes of LELC in our local population.

Since first described by Begin et al in 1987, only approximately 200 cases have been reported so far globally over last 3 decades, highlighting its rarity $[8,16]$. With an incidence of 1500 new cases of lung cancer every year in Singapore, the estimated incidence in our population is $0.1 \%$.

Although the gender predilection of LELC varies, our cohort showed a female predominance with predilection for non-smokers in keeping with the published literature. Chang et al from Taiwan [17], Liang et al from China [8], and Tay et al from Singapore [26] described female predominance in their cohorts similar to ours, whereas Han et al from China described male preponderance [19].

Median age in our cohort was 62 (42-88) years. Previous studies reported the median age of LELC patients to range from $47-58$ years $[15,17,18,20,26]$. The median age in our cohort was older than those in previous studies but still younger than the reported median age of 70 years for NSCLC, asserting the onset of LELC at a younger age. The older age of the patients in our cohort could be the reflection of the catchment area of our hospital as it lies in the district with the highest number of residents above the age of 65 years [28].

All patients in our cohort were positive for EBV-encoded small non-polyadenylated RNA (EBER), affirming the association between EBV and pulmonary LELC in keeping with the existing literature. Most LELC cases reported in the literature are positive for EBER on in situ hybridization $[14,26]$. In addition, Chang et al reported that a higher EBV serology titre represented higher tumour stage and larger tumour size [17]. Due to this, primary pulmonary LELC can be histologically indistinguishable from EBV associated LELC occurring in the nasopharynx (NPC) in Asian population [14, 21]. It is therefore necessary to differentiate NPC with metastasis to lung, from an early stage primary pulmonary LELC where surgical resection is recommended. Hence, all our patients were screened and cleared by ear, nose, and throat (ENT) surgeons for any concurrent nasopharyngeal involvement. 
The majority of patients (60\%) in our cohort had advanced (stage IV) pulmonary LELC. This is in contrast to the reports from China, Taiwan, and Hong Kong, where the majority of patients presented with early stage and only a minority presented with stage IV disease $[8,17,27]$. However, our results are in keeping with the study from Tay et al [26]. Additionally, at our centre, all lung cancer patients are initially staged using PET/CT of the body and MRI of the brain. Although unconfirmed, one of the reasons for the more advanced stage in our cohort could have been the up-staging of these cancers. This makes a direct comparison with previous reports difficult, where less sensitive and specific imaging techniques could have been used.

LELC is reported to be chemosensitive and radiosensitive cancer [22]. Seven patients were treated with chemotherapy in our cohort out of which $5(71.4 \%)$ received gemcitabine/carboplatin as first line chemotherapy consistent with the published literature. Although the choice of first line chemotherapy was largely an extrapolation from chemotherapy used for NPC, it had shown to offer high disease control rate. Previous studies described good outcomes in patients with multimodality treatment [23]. Ho et al noted that 5-fluorouracil (5-FU)/cisplatin (FLP) demonstrated a high tumour response rate (60\% partial response), with a median survival of $23.4+/-4.7$ months [24]. Liang et al also reported that various regimes of chemotherapy such as paclitaxel/docetaxel + cisplatin/carboplatin, pemetrexed + cisplatin, gemcitabine + cisplatin, docetaxel/paclitaxel + cisplatin + 5-fluorouracil, gemcitabine + vinorelbine in advanced pulmonary LELC had a high disease control rate (>75\%) [8].

The median (range) overall survival in our cohort was 24.2 (4.7-59.4) months with 1-year, 2-year, 3-year, and 5 -year survival rates of $90 \%, 50 \%, 30 \%$, and $10 \%$ respectively. Previous reports from China, Hong Kong, Taiwan, and Singapore have described median overall survival rates of $31,39.1,23.4,27.6$, and 43 months $[5,8,23,24,26]$. In a study of 52 patients (the largest study) with advanced LELC from China receiving chemotherapy (with or without radiotherapy), 1-year, 2-year, and 3-year survival rates of $100 \%$, $76 \%$, and $61 \%$ were reported [8]. The 2-year and 5-year survival rates described in another study from China were $90 \%$ and $74 \%$, whereas a Singaporean study described 2-year and 5-year survival rates of $78.6 \%$ and $54.9 \%[25,26]$. Worse overall survival rates were seen in patients with higher grading and more advanced tumours [25]. Although the median overall survival and 1-year survival rate in our study were similar, the 2-year and 5-year survival rate in our cohort was lower. This is likely due to the greater proportion of patients with stage IV as well as the refusal of or being unfit to receive chemotherapy in patients with early stages.

When analysed by stage, the median survival in stage II, IIIA, and IV was 27.6, 20.7 (19.8-48.9), and 26.6 (4.7-59.4) months respectively. This is higher compared to NSCLC, where the median survival for stage III and IV is 13.7 , and 4 months respectively $[29,30]$. The stage by stage comparison with survival data for LELC from other studies showed that our median survival was lower but still significantly higher than the corresponding stages for NSCLC as a whole.

Thus, our cohort demonstrated similarities and differences from other existing literature which may be due to our study limitations. It is a retrospective, single centre study with a small sample size. However, in 
view of the rarity of this subtype of lung cancer, our study highlights the biological characteristics of LELCs and demonstrated the better survival of these patients, adding to the growing body of evidence and understanding of this rare condition. The biology of LELCs appears to be similar to NPC patients and it is therefore reasonable to consider therapeutic options available for NPC. One such consideration would be the use of adoptive immunotherapy once the results of the on-going phase III trial re-infusing EBV-specific autologous cytotoxic T-lymphocytes are known [31]. The publication of this trial is eagerly awaited. Another consideration would be to use EBV vaccination against virulent EBV antigens such as LMP2 potentially together with other treatment modalities [32].

In conclusion, comparing our study to the reports from China, Hong Kong, and Taiwan, our cohort was similar in terms of low incidence of LELC, Chinese preponderance, association with EBV, lack of smoking, younger age of onset and improved survival compared to other subtypes of lung cancer. Our study differed in terms of older patients, patients with more advanced stage disease, and henceforth an inherent poorer survival. For improving outcomes, future efforts should focus on increased awareness, early diagnosis, development of an ASEAN registry and international collaboration. Options such as EBVdirected adopted immunotherapy or the role of EBV vaccine also merit evaluation.

\section{Abbreviations}

LELC: Iymphoepithelioma-like carcinoma; EBV: Epstein Barr Virus; EBER: Epstein-Barr virus encoded small non-polyadenylated ribonucleic acid; ASEAN: Association of Southeast Asian Nations; NSCLC: Non-small cell lung cancer; TKI: Tyrosine kinase inhibitor; NPC: Nasopharyngeal carcinoma; PTLD: Post-transplant lymphoproliferative diseases; BL: Burkitt`s lymphoma; DLBCL: Diffuse large B cell lymphoma; ECOG: Eastern Cooperative Oncology Group; EBUS-TBNA: Endobronchial ultrasound guided transbronchial needle aspiration; LMP2: Latent membrane protein 2.

\section{Declarations}

Ethics Approval: Approval from the institutional review board, domain specific review board (DSRB) was obtained. DSRB Ref 2019/00955

Consent for publication: Not applicable

Availability of data and materials: The datasets used and/or analysed during the current study are available from the corresponding author on reasonable request.

Competing interest: J.D., D.Y.H.T., J.S., S.K.G., A.C.K., Y.K.Z., D.C., S.J.W., O.K.C., and A.V. have no competing financial interests to disclose.

Funding: This study was retrospective and hence did not receive any funding. 
Contribution of authors: Conceptualisation : AV \& JS. Data collection \& analysis: JD \& AV. Drafting the manuscript : DYHT, SKG, ACK, YKZ, DC, JWS. Critical review and revision of the manuscript: DYHT, YKZ, DC, SJW, OKC.

Acknowledgment: Authors would like to thank Dr. Chua Khoon Leong, and Ms. Ivy Yu Ling Ling, for their valuable contribution in preparing the figures and the administrative work.

\section{References}

1. Freddie Bray, Jacques Ferlay, Isabelle Soerjomataram, et al. Global Cancer Statistics 2018 : GLOBOCAN Estimates of incidence and mortality worldwide for 36 cancers in 185 countries. Cancer J Clin 2018;68:394-24.

2. Mindy C. DeRouen, Lauren Hu, and Meg McKinley, et al. Incidence of lung cancer histologic cell-types according to neighborhood factors: A population based study in California. PLoS One 2018; 13: e0197146.

3. Brambilla E, Pugatch B, Geisinger K, et al. WHO Classification of tumours pathology \& genetics tumours of the lung, pleura, thymus and heart.IARC Press; Lyon: 2004.

4. Mo Y, Shen J, and Zhang Y, et al. Primary lymphoepithelioma-like carcinoma of the lung: Distinct computed tomography features and associated clinical outcomes. J Thorac Imaging 2014; 29:24651.

5. Lan Lin, Tingyan Lin and Bangwei Zeng. Primary lymphoepithelioma-like carcinoma of the lung: An unusual cancer and clinical outcomes of 14 patients. Oncology Letters 2017; 14: 3110-16.

6. Hesborn Wao, Rahul Mhaskar, Ambuj Kumar, et al. Survival of patients with non-small cell lung cancer without treatment: A systematic review and meta-analysis. Systematic Reviews 2013; 2:10

7. Chee Keong Toh, Whee Sze Ong, Daniel SW Tan, et al. Improved Survival of Advanced Lung cancer in Singapore over the past decade. Ann Acad Med Singapore 2017;46:333-8

8. Liang Y, Wang L, Zhu Y, et al. Primary pulmonary lymphoepithelioma-like carcinoma: fifty-two patients with long-term follow-up. Cancer2012; 118:4748-58.

9. Wei WI, Sham JS. Nasopharyngeal carcinoma. Lancet 2005; 365:2041-54.

10. Smatti MK, Al-Sadeq DW, Nadima H. Ali, et al. Epstein-Barr Virus epidemiology, serology, and genetic variability of LMP-1 oncogene among healthy population: An update. Front Oncol 2018; 8: 211.

11. Castro CY, Ostrowski ML, Barrios R, et al. Relationship between Epstein-Barr virus and lymphoepithelioma-like carcinoma of the lung: A clinicopathologic study of 6 cases and review of the literature. Hum Pathol 2001; 32: 863-72.

12. TzellosS, Farrell PJ. Epstein - Barr virus sequence variation biology and disease. Pathogens 2012; 1: 156-75.

13. Ho JC, Wong MP, Lain WK. Lymphoepithelioma-like carcinoma of the lung. Respirol 2006; 11: 539-45. 
14. Han AJ, Xiong M, Zong YS. Association of Epstein-Barr virus with lymphoepithelioma-like carcinoma of the lung in southern China. Am J Clin Pathol 2000; 114: 220-6.

15. Huang CJ, Feng AC, Fang YF, et al. Multimodality treatment and long-term follow-up of the primary pulmonary lymphoepithelioma-like carcinoma.Clin Lung Cancer 2012; 13:359-62.

16. Begin LR, Eskandari J, Joncas J, et al. Epstein - Barr virus related lymphoepithelioma-like carcinoma of lung. J Surg Oncol 1987; 36: 280-3.

17. Chang YL, Wu CT, Shih JY, et al. Unique p53 and epidermal growth factor receptor gene mutation status in 46 pulmonary lymphoepithelioma-like carcinomas. Cancer Sci 2011; 102:282-7.

18. Lin Z, Situ D, Chang $X$, et al. Surgical treatment for primary pulmonary lymphoepithelioma-like carcinoma. Interact Cardiovasc Thorac Surg 2016; 23:41-6.

19. Han AJ, Xiong M, Gu YY, et al. Lymphoepithelioma-like carcinoma of the lung with a better prognosis. A clinicopathologic study of 32 cases.Am J Clin Pathol 2001; 115:841-50.

20. Sun YH, Lin SW, Hsieh CC, et al. Treatment outcomes of patients with different subtypes of large cell carcinoma of the lung. Ann Thorac Surg 2014; 98:1013-9.

21. Chan JK, Hui PK, Tsang WY, et al. Primary lymphoepitheliomalike carcinoma of the lung. A clinicopathologic study of 11 cases. Cancer 1995; 76:413-22.

22. Chan T C, Teo M L, Lam K C, et al. Multimodality treatment of primary lymphoepithelioma-like carcinoma of the lung. Cancer 1998; 83: 925-9.

23. Lin $\mathrm{CY}$, Chen YJ, Hsieh MH, et al. Advanced primary pulmonary lymphoepithelioma-like carcinoma: clinical manifestations, treatment, and outcome. J Thorac Dis 2017; 9:123-8.

24. Ho JC, Lam WK, Wong MP, et al. Lymphoepithelioma-like carcinoma of the lung: experience with ten cases. Int J Tuberc Lung Dis 2004; 8:890-5.

25. Jiang WY, Wang R, Pan XF, et al. Clinicopathological features and prognosis of primary pulmonary lymphoepithelioma-like carcinoma. J Thorac Dis 2016; 8: 2610-16.

26. Tay CK, Chua YC, Takano A, et al. Primary pulmonary lymphoepithelioma-like carcinoma in Singapore. Ann Thorac Med 2018; 13:30-5.

27. Ngan RK, Yip TT, Cheng WW, et al. Clinical role of circulating Epstein-Barr virus DNA as a tumour marker in lymphoepithelioma-like carcinoma of the lung. Ann N Y Acad Sci 2004; 1022:263-70.

28. Statistics Singapore Population Trends 2018. Available at https://www.singstat.gov.sg/-/media/files/publications/population/population2018.pdf

29. Dillman RO, Herndon J, Seagren SL, et al. Improved survival in stage III non-small-cell lung cancer: seven-year follow-up of cancer and leukaemia group B (CALGB) 8433 trial. J Natl Cancer Inst 1996; 88:1210-5.

1. Karynsa Cetin, David S Ettinger, Yong-jiang Hei, et al. Survival by histologic subtype in stage IV nonsmall cell lung cancer based on data from the Surveillance, Epidemiology and End Results Program. Clin Epidemiol 2011; 3: 139-48. 
1. An open-label, randomized phase III trial of gemcitabine and carboplatin (GC) followed by EpsteinBarr virus-specific autologous cytotoxic t lymphocytes (EBV-CTLs) versus GC as front-line therapy for patients with advanced nasopharyngeal carcinoma. J Clin Oncol2018 36:15_suppl, 6082-6082.

1. Progress in EBV Vaccines. Zyl DG, Mautner J, Delecluse HJ. Front. Oncol 2019 https://doi.org/10.3389/fonc.2019.00104

1. Lee AW, Sze WM, Au JS, et al. Treatment results for nasopharyngeal carcinoma in the modern era: The Hong Kong experience. Int J Radiat Oncol Biol Phys 2005; 61:1107.

\section{Tables}

Table 1. Baseline characteristics of the pulmonary LELC patients 


\begin{tabular}{|c|c|c|}
\hline Variable & Category & $\mathbf{N}(\%)$ \\
\hline Patients & Total number & 10 \\
\hline Age at diagnosis & Years & $\begin{array}{l}62(42- \\
88)\end{array}$ \\
\hline \multirow[t]{2}{*}{ Gender } & Male & $2(20)$ \\
\hline & Female & $8(80)$ \\
\hline Race & Asian & $10(100)$ \\
\hline \multirow[t]{3}{*}{ Smoking } & Yes & $2(20)$ \\
\hline & No & $7(70)$ \\
\hline & Unknown & $1(10)$ \\
\hline \multirow[t]{2}{*}{ ECOG status } & 0 & $6(60)$ \\
\hline & 1 & $4(40)$ \\
\hline \multirow[t]{2}{*}{ Tumour Size } & $<3 \mathrm{~cm}$ & $\begin{array}{l}1 \\
(10)\end{array}$ \\
\hline & $>3 \mathrm{~cm}$ & $9(90)$ \\
\hline \multirow[t]{4}{*}{ Stage } & I & $0(0)$ \\
\hline & II A & $1(10)$ \\
\hline & III A & $3(30)$ \\
\hline & IV & $6(60)$ \\
\hline \multirow[t]{4}{*}{ Primary site } & Lung, NOS & $3(30)$ \\
\hline & Upper lobe, lung & $1(10)$ \\
\hline & Middle lobe, lung & $0(0)$ \\
\hline & Lower lobe, lung & $6(60)$ \\
\hline \multirow{3}{*}{$\begin{array}{l}\text { Mode of diagnostic } \\
\text { investigation }\end{array}$} & EBUS- TBNA & $5(50)$ \\
\hline & TTNA & $3(30)$ \\
\hline & Biopsy of non-pulmonary metastatic Site & $2(20)$ \\
\hline \multirow[t]{3}{*}{ Therapeutic modality } & Palliative chemotherapy & $7(70)$ \\
\hline & $\begin{array}{l}\text { Radiation therapy (Isolated or in combination with } \\
\text { chemo) }\end{array}$ & $5(50)$ \\
\hline & Declined chemotherapy & $2(20)$ \\
\hline
\end{tabular}


Data presented as number (\%) or median (range)

ECOG: Eastern Cooperative Oncology Group, NOS: Not otherwise specified, EBUS-TBNA: Endobronchial ultrasound guided Transbronchial needle aspiration, TTNA: Transthoracic needle aspiration Table 2. Clinical information of 10 patients with pulmonary LELC. 


\begin{tabular}{|c|c|c|c|c|c|c|c|}
\hline $\begin{array}{l}\text { Case no. } \\
\text { /sex/age } \\
\text { years/race }\end{array}$ & $\begin{array}{l}\text { Smoking } \\
\text { history }\end{array}$ & $\begin{array}{l}\text { Tumour } \\
\text { location }\end{array}$ & $\begin{array}{l}\text { Size in } \\
\mathrm{cm}\end{array}$ & $\begin{array}{l}\text { TNM } \\
\text { stage }\end{array}$ & EBER & Treatment & $\begin{array}{l}\text { Outcome } \\
\text { (Alive/Deceased) }\end{array}$ \\
\hline $1 / F / 53 / C$ & No & RLL & $3.0 \times 4.0$ & $\begin{array}{l}\text { IVB } \\
\text { (T3 } \\
\text { N3 } \\
\text { M1c) }\end{array}$ & + & $\begin{array}{l}\text { ChT (GP } \\
\times 6, P C \times 6) \\
+R T\end{array}$ & $\begin{array}{l}\text { Alive, } 59.4 \\
\text { months }\end{array}$ \\
\hline $2 / \mathrm{M} / 63 / \mathrm{C}$ & Yes & RLL & $9.3 \times 7.4$ & $\begin{array}{l}\text { IVB } \\
\text { (T4 } \\
\text { N2 } \\
\text { M1c) }\end{array}$ & + & $\begin{array}{l}\text { ChT (GP } \\
\mathrm{x} 14)\end{array}$ & $\begin{array}{l}\text { Deceased, } 32.4 \\
\text { months }\end{array}$ \\
\hline $3 / F / 65 / C$ & No & LLL & $8.0 \times 5.0$ & $\begin{array}{l}\text { IIIA } \\
\text { (T3 } \\
\text { N0 } \\
\text { M0) }\end{array}$ & + & $\begin{array}{l}\text { ChT (GP } \\
\times 6, C \times 6) \\
+R T\end{array}$ & $\begin{array}{l}\text { Deceased, } 20.7 \\
\text { months }\end{array}$ \\
\hline $4 / \mathrm{M} / 52 / \mathrm{C}$ & Yes & BLN & $2.0 \times 1.4^{*}$ & $\begin{array}{l}\text { IVA } \\
\text { (T1b } \\
\text { N2 } \\
\text { M1a) }\end{array}$ & + & $\begin{array}{l}\text { ChT (GP } \\
\text { x6, N x3, D } \\
\text { x3) +RT }\end{array}$ & $\begin{array}{l}\text { Deceased, } 20.8 \\
\text { months }\end{array}$ \\
\hline $5 / F / 49 / C$ & No & LSH & $6.2 \times 5.3$ & $\begin{array}{l}\text { IVA } \\
\text { (T3 } \\
\text { N2 } \\
\text { M1b) }\end{array}$ & + & $\begin{array}{l}\text { ChT (GP } \\
\times 6, P a c \times 4, \\
D \times 3)\end{array}$ & $\begin{array}{l}\text { Deceased, } 16.9 \\
\text { months }\end{array}$ \\
\hline $6 / F / 42 / C$ & No & RUL & $6.4 \times 6.3$ & $\begin{array}{l}\text { IVA } \\
\text { (T3 } \\
\text { N2 } \\
\text { M1a) }\end{array}$ & + & $\begin{array}{l}\text { ChT (PPB } \\
\times 6, G \times 6)\end{array}$ & $\begin{array}{l}\text { Alive, } 49.5 \\
\text { months }\end{array}$ \\
\hline 7/F/73/C & Unknown & MS & $6.9 \times 4.7$ & $\begin{array}{l}\text { IIIA } \\
\text { (T3b } \\
\text { N1 } \\
\text { M0) }\end{array}$ & + & $\begin{array}{l}\text { SG, RT, } \\
\text { declined } \\
\text { ChT. }\end{array}$ & $\begin{array}{l}\text { Alive, } 48.9 \\
\text { months }\end{array}$ \\
\hline 8/F/88/C & No & RLL & $5.0 \times 4.8$ & $\begin{array}{l}\text { IIA } \\
\text { (T2b } \\
\text { N0 } \\
\text { M0) }\end{array}$ & + & $\begin{array}{l}\text { RT, unfit } \\
\text { for } \\
\mathrm{ChT} / \mathrm{SG}\end{array}$ & $\begin{array}{l}\text { Deceased, } 27.6 \\
\text { months }\end{array}$ \\
\hline $9 / F / 67 / C$ & No & RLL & $9.1 \times 8.9$ & $\begin{array}{l}\text { IVB } \\
\text { (T4 } \\
\text { N2 } \\
\text { M1c) }\end{array}$ & + & $\begin{array}{l}\text { Declined } \\
\text { treatment }\end{array}$ & $\begin{array}{l}\text { Deceased, } 4.7 \\
\text { months }\end{array}$ \\
\hline $10 / F / 61 / C$ & No & LLL & $4.6 \times 3.9$ & $\begin{array}{l}\text { IIIA } \\
\text { (T2b } \\
\text { N2 } \\
\text { M0) }\end{array}$ & + & $\begin{array}{l}\text { ChT (GP } \\
\times 6, N \times 2, D \\
x 1)\end{array}$ & $\begin{array}{l}\text { Deceased, } 19.8 \\
\text { months }\end{array}$ \\
\hline
\end{tabular}

TNM, tumour-node-metastasis; F, female; $M$, male; C, Chinese; RLL, right lower lobe of lung; LLL, left lower lobe; BLN, bilateral lung nodules; $L S H$, left suprahilar; RUL, right upper lobe of lung; MS, mediastinal; $R H$, right hilum; +, positive; SG, surgery; ChT, chemotherapy; RT, radiotherapy; EBER, Epstein-Barr virus-encoded 
RNA; D, docetaxel; PPB, pemetrexed + cisplatin + bevacizumab; GP, gemcitabine + carboplatin/cisplatin; P, cisplatin/carboplatin; C, Capecitabine; LELC, lymphoepithelioma-like carcinoma N; Nivolumab, Pac; paclitaxel. * largest among multiple nodules.

\section{Figures}

(a)

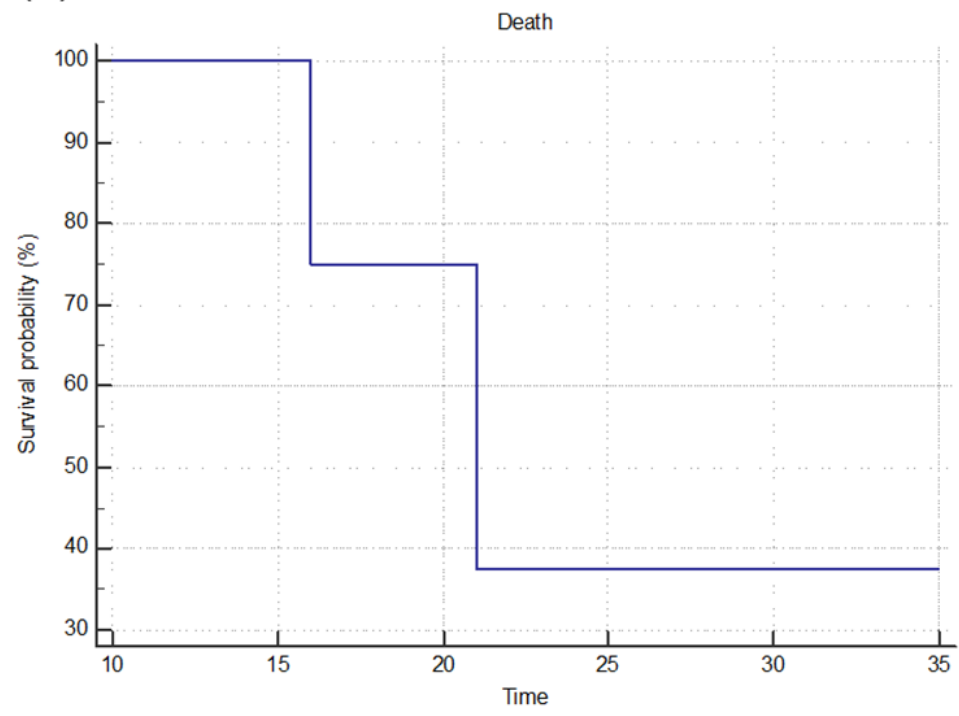

(b)

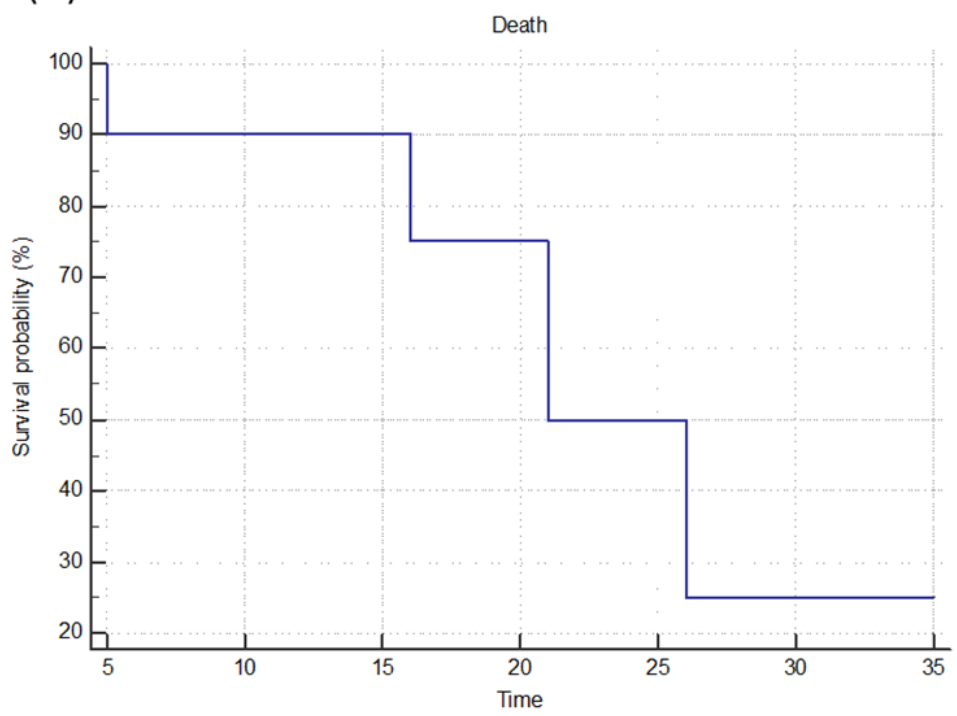

Figure 1

A) Kaplan-Meier Survival Curve for the 10 patients with LELC. B) Kaplan-Meier survival curve for the 7 patients with advanced LELC who received palliative chemotherapy. 


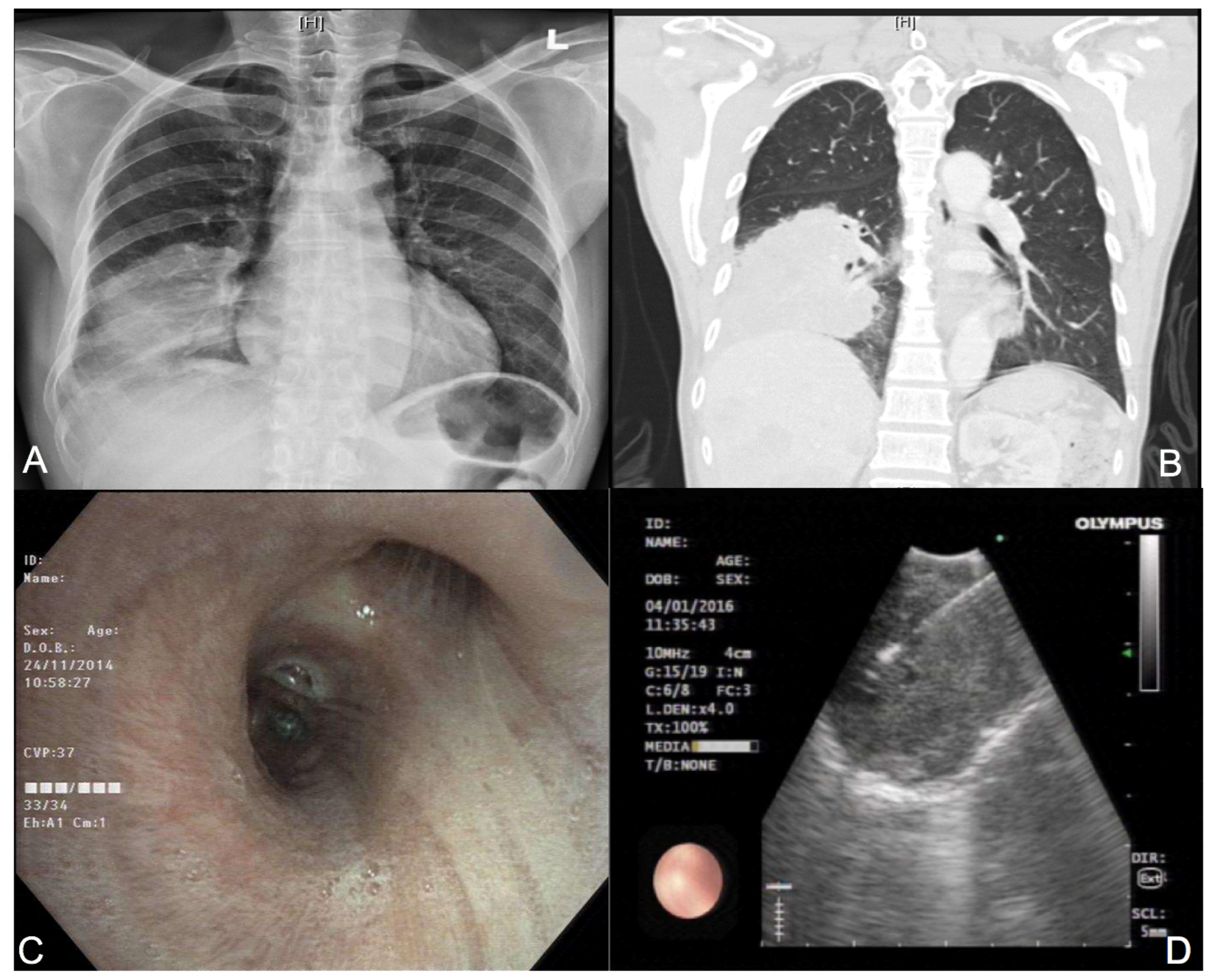

Figure 2

A) Chest radiograph with right lower zone consolidation. B) Computed tomography with large right lower lobe mass lesion. C) Endoscopic image of right main bronchus with no Endobronchial lesions. D) EBUS TBNA of station 4R Lymph node. 


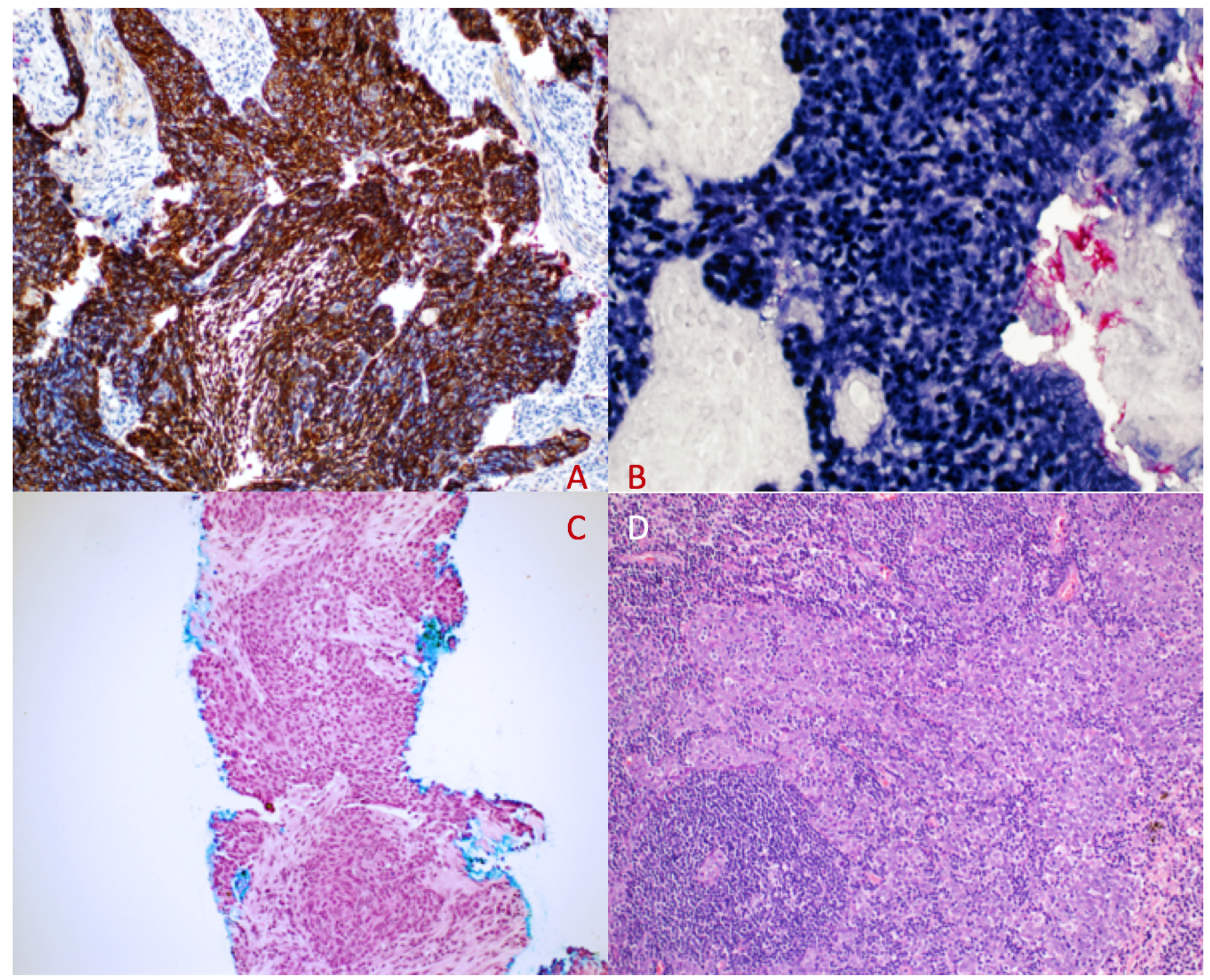

\section{Figure 3}

Epstein-Barr virus encoded small non-polyadenylated ribonucleic acid in situ hybridization (EBER-ISH) was positive in all cases. The histopathological representation of some of the patients in this cohort is shown below. A) Biopsy from lung revealing clusters of elongated epithelial cells with prominent nucleoli in some areas associated with a desmoplastic stroma. (H\&E, original magnification $\times 200)$. B) Tumour cells decorated by antibody against high molecular weight cytokeratin CK5/6. (Optiview detection kit, Ventana. Original magnification $\times 200)$. C) Diffuse positive signals within nuclei of tumour cells on EBERISH. (Iview blue detection kit, Ventana. Original magnification x400). D) Lymph node affected by metastatic lymphoepithelioma like carcinoma. Note the indistinct cytoplasmic borders and prominent nucleoli. (H\&E, original magnification x400). 